\title{
Long-term survival after use of internal thoracic artery in octogenarians is gender related
}

\author{
Arun K. Singh, MD, FRCS(C), Andrew D. Maslow, MD, Jason T. Machan, PhD, James G. Fingleton, MD, \\ William C. Feng, MD, Carl Schwartz, MD, Fred A. Rotenberg, MD, and Arthur A. Bert, MD
}

\begin{abstract}
Objective: The goal of this study is to assess the benefits of a left internal thoracic artery as a bypass conduit in octogenarians undergoing elective coronary artery bypass grafting. We hypothesize that there is no survival advantage and that outcome may be gender related.
\end{abstract}

Methods: In a retrospective analysis of 1141 octogenarians (aged $>80$ years) undergoing isolated coronary artery bypass grafting from 1996 to 2012, patients were divided into 2 groups: Group I (coronary artery bypass grafting-left internal thoracic artery) included 870 patients (339 female/531 male), and group II (coronary artery bypass grafting-saphenous vein graft) included 271 patients (131 female/140 male).

Results: The overall 30-day mortality was 5.7\%: 4.3\% in group I and $7.0 \%$ in group II $(P=.1)$. Group II had a lower trend of any postoperative complication $(P=.05)$ and pneumonia $(P=.05)$. When analyzed by gender, there were no discernable differences in long-term survival for male patients in group I $(65 \%$ at 5 years and $29 \%$ at 10 years) versus male patients in group II (65\% at 5 years and $31 \%$ at 10 years $)(P=.2)$. However, survival was significantly greater for female patients in group I ( $70 \%$ at 5 years and $35 \%$ at 10 years) versus female patients in group II $(63 \%$ at 5 years and $21 \%$ at 19 years $)(P=.01)$. Multiple logistic and Cox regression analysis showed that left internal thoracic artery use is associated with improved survival in female patients (hazard ratio [HR], 0.72 ; confidence interval [CI], 0.56-0.93) but not in male patients (HR, 1.14; CI, 0.9-1.4). Advanced age was associated with an increased risk of mortality (HR, 1.08 per year; CI, 1.05-1.1). Both patient age $(P=.01)$ and Society of Thoracic Surgeons-predicted 30-day mortality $(P=.03)$ remain in the final model for 30-day mortality. The benefit of the left internal thoracic artery after coronary artery bypass grafting in octogenarians may be gender related.

Conclusions: This study shows that the benefit of the left internal thoracic artery in the octogenarian population undergoing coronary artery bypass grafting may be gender related. For elderly female patients, the use of the left internal thoracic artery as a bypass conduit was associated with better long-term survival, whereas no significant difference was found among the male population. The use of the left internal thoracic artery was associated with a greater postoperative pulmonary morbidity for the study population as a whole. The present study does not refute the benefit of the left internal thoracic artery-left anterior descending graft, but instead distinguishes a subset who might benefit more. ( $\mathrm{J}$ Thorac Cardiovasc Surg 2015;150:891-9)

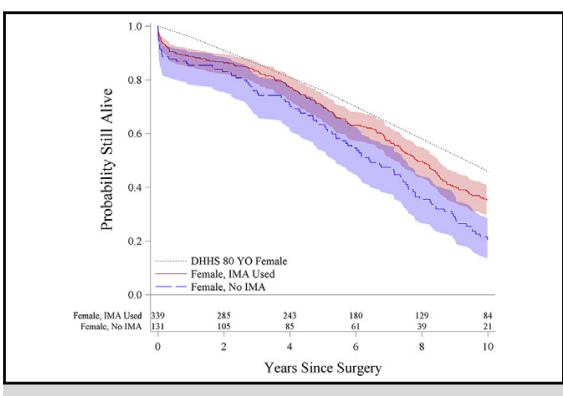

Time-varying outcome (survival curve): 10 years in female patient with ITA versus SVG.

\section{Central Message}

The benefit of the ITA after CABG in octogenarians may be gender related.

\section{Perspective}

In octogenarians, ITA use may improve longterm survival benefits in women but not in men. Use of the ITA in this population is associated with increased pulmonary complications. In frail octogenarians, use of an SVG instead of an ITA may be a justified alternative. The benefit of the ITA after CABG in octogenarians may be gender related.

See Editorial Commentary page 900

\footnotetext{
From the Department of Surgery and Department of Anesthesiology, Rhode Island Hospital/Lifespan, Alpert Medical School of Brown University, Providence, RI.

Received for publication March 17, 2015; revisions received July 1, 2015; accepted for publication July 18, 2015; available ahead of print Aug 25, 2015.

Address for reprints: Arun K. Singh, MD, FRCS(C), Two Dudley St, Suite 360,

Providence, RI 02903 (E-mail: asingh@lifespan.org).

$0022-5223 / \$ 36.00$

Copyright (c) 2015 by The American Association for Thoracic Surgery

http://dx.doi.org/10.1016/j.jtcvs.2015.07.052
}

Octogenarians (aged $>80$ years) represent the fastest growing segment of our population. Symptomatic cardiovascular disease is present in as many as $40 \%$ of octogenarians and accounts for more than half of the mortality in this age group. ${ }^{1,2}$ Recent data ${ }^{2-4}$ have indicated improved long-term survival in octogenarians with multivessel coronary artery stenosis undergoing 


$$
\begin{aligned}
& \text { Abbreviations and Acronyms } \\
& \begin{aligned}
\text { BMI } & =\text { body mass index } \\
\text { CABG } & =\text { coronary artery bypass grafting } \\
\text { CI } & =\text { confidence interval } \\
\text { HR } & =\text { hazard ratio } \\
\text { ITA } & =\text { internal thoracic artery } \\
\text { LAD } & =\text { left anterior descending } \\
\text { STS } & =\text { Society of Thoracic Surgeons } \\
\text { SVG } & =\text { saphenous vein graft }
\end{aligned}
\end{aligned}
$$

coronary artery bypass grafting (CABG) versus percutaneous interventions. As a result, this group presents frequently for CABG.

Use of the left internal thoracic artery (ITA) as a conduit to bypass a critical stenosis of the left anterior descending (LAD) artery (ITA-LAD) during myocardial revascularization has become a standard technique for patients undergoing $\mathrm{CABG}$, as well as a marker of quality of a cardiac surgeon or cardiac surgical program. ${ }^{5}$ However, because of concern of greater perioperative morbidity, there may be hesitation for routine use of the ITA in the octogenarian population. ${ }^{6}$ Patient gender is a known risk factor for in-hospital death and long-term survival after $\mathrm{CABG}^{7}$ Men and women have different hormonal and disease profiles, and men tend to have larger coronary arteries. To date, no large studies have analyzed long-term survival by the gender of patients undergoing isolated CABG with or without ITA in octogenarians.

The goal of this study is to assess the effect of gender regarding the outcome after the use of the ITA or vein graft in octogenarians undergoing elective, isolated CABG. Patients receiving ITAs were compared with those receiving vein grafts with regard to operative survival and complications, stratifying by gender in anticipation of differential effects in men and women.

\section{MATERIALS AND METHODS}

From January 1996 to December 2012, at Lifespan institutions, 12,086 isolated $\mathrm{CABG}$ procedures were performed with a 30-day postoperative mortality rate of $2.1 \%$. These data are inclusive of 1141 isolated, nonemergency $\mathrm{CABG}$ procedures performed in octogenarian patients (aged $>80$ years) with a body mass index (BMI) less than $50 \mathrm{~kg} / \mathrm{m}^{2}$.

We conducted a retrospective study of octogenarian patients who had undergone elective primary isolated CABG surgery. Patients undergoing cardiac surgical procedures other than isolated $\mathrm{CABG}$, reoperation, renal failure on dialysis, or CABG without cardiopulmonary bypass were excluded. Patient demographics, operative variables, and perioperative outcomes were collected prospectively at the time of initial operative care. Long-term outcome data were extracted through a review of hospital medical records, physician office records, and the Society of Thoracic Surgeons (STS) National Cardiac Database ${ }^{8}$ and cardiac catheterization laboratory (Apollo system). This study was approved by the institutional review board. The patients were identified as patients who received at least 1 ITA as a conduit to the LAD (CABG-ITA: group I), in addition to any vein grafts, or as patients who received only saphenous vein graft (SVG) bypass (CABG-SVG: group II). Patients were also subgrouped by gender.

\section{Surgical Procedure}

The indications for surgery included refractory angina or compelling anatomy. The surgical goal was a complete revascularization of coronary artery territory lesions with greater than $70 \%$ stenosis and a native distal vessel with a diameter greater than $1 \mathrm{~mm}$. Bypasses were not performed on diffusely diseased native coronary arteries without a discrete lesion and a suitable distal target vessel.

The decision to use an ITA or a saphenous vein as a conduit for the diseased (LAD) artery was at the surgeons' discretion. The cited reasons for not using the ITA include previous external beam radiation to the chest, known critical left subclavian artery stenosis with poor flow through the ITA, severe obstructive lung disease, hemodynamic instability during surgery, or generalized frailty.

Frailty was based on the surgeon's assessment of sternal/bone quality and general evaluation of functionally and nutritional status preoperatively. Group II (non-ITA use group) was not further subdivided on the basis of the reason for not using the ITA. Routine standard frailty tests were not carried out preoperatively.

All surgeries were performed using cardiopulmonary bypass with normothermic perfusion and intermittent antegrade/retrograde cold blood cardioplegia as previously described. ${ }^{9}$ The ITA was dissected and used as an in situ pedicle graft. Saphenous veins were harvested from the lower leg using multiple small incisions and a "no touch" surgical technique or harvested endoscopically with the VasoView technique (Maquet, Wayne, NJ). A branchless portion of the lower leg saphenous vein was used as the preferred conduit for anastomosis to the LAD when the ITA was not harvested.

\section{Data Collection}

Long-term follow-up for mortality data was accomplished by contacting the patient, family member, or the patient's primary care physicians or cardiologists, and local newspaper death notices. Mortality data were updated continuously and assessed using the Social Security Death Index. The follow-up was $99 \%$ complete.

Study end points included perioperative (30-day) mortality, postoperative stroke, myocardial infarction, reoperation for bleeding, prolonged ventilation, pulmonary complications, renal failure, renal dialysis, and deep tissue wound infection. These morbidities were collected prospectively and defined according to STS National Cardiac Database criteria with mortality scoring based on the most recent STS score calculator (2002-2006).

\section{Statistical Methods}

Patients undergoing myocardial revascularization using the ITA (group I: CABG-ITA) were compared with those in whom the ITA was not used (group II: CABG-SVG) using generalized linear models. All parameters in Figure 1 and Tables 1 to 4 are presented with their 95\% confidence intervals (CIs). Dichotomous dependent variables (eg, stroke) were modeled as binary. Continuous dependent variables were modeled as (1) Gaussian (BMI) and (ejection fraction), (2) exponential (age), (3) Poisson (number of grafts), (4) binomial (STS risk mortality), or (5) negative binomial (age, perfusion time, crossclamp time) on the basis of examination of model residuals. Classic sandwich estimation was used to further adjust for any differences between the distribution of the data and the idealized statistical distribution on which the model was based. No hypothesis test was carried out for binary dependent variables with zero counts in 1 or more groups. Alpha was not adjusted for multiplicity because the nature of the analysis was such that conclusions drawn from null findings created by such adjustment would be interpreted as liberal. The 3-category formulation of ejection fraction 

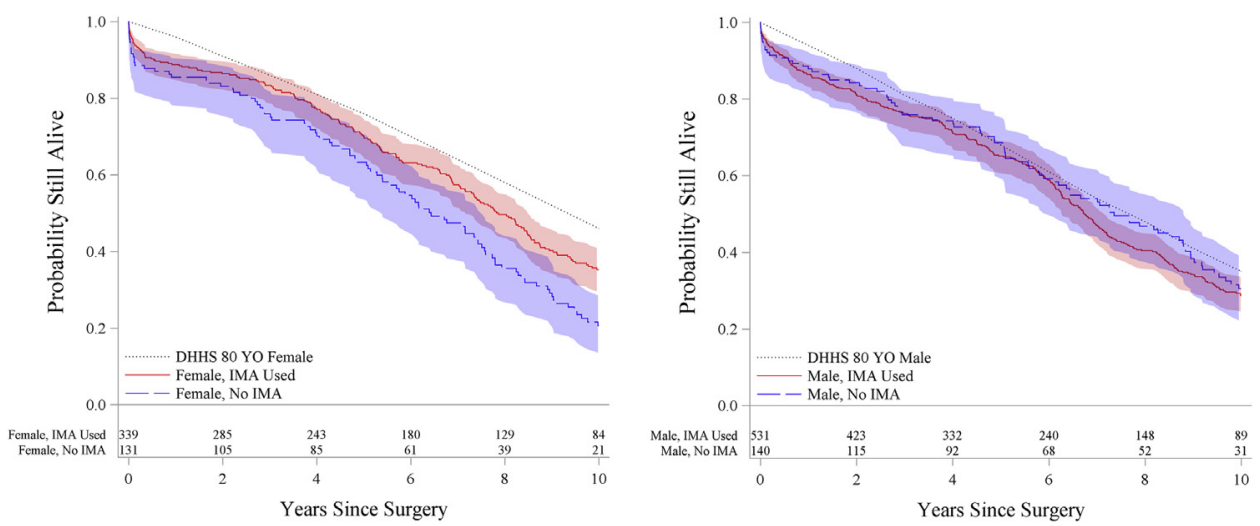

FIGURE 1. Kaplan-Meier estimated survival function of overall mortality for male (blue) and female (red) patients who received ITA (solid) and SVG (dash) grafts along with US Department of Health and Human Services life expectancy (did extend 16 years) for men and women aged 80 years. The biennial count of patients remaining in each strata is provided as an insert table. Female patients who received ITAs (solid red, 5 years: 70\%, 10 years: $35 \%$ ) had a survival advantage $(P=9.9987)$ over female patients who did not (SVGs) (dash red, 5 years: 63\%, 10-years: $21 \%)$. In contrast, male patients who received ITAs (solid blue, 5 years: $65 \%, 10$ years: $29 \%$ ) did not have a statistically significant survival advantage $(P=.2385)$ over male patients who received SVGs (dash blue, 5 years: 69\%, 10 years: 31\%). DHHS, Department of Health and Human Services; ITA, internal thoracic artery; YO, year old.

and STS 30-day predicted mortality was compared using the chi-square test.

Time-to-event outcomes (length of stay, 30-day mortality, and overall mortality) were initially modeled using Kaplan-Meier estimates as a function of gender and whether the ITA was used with curves compared using Wilcoxon weighting. Deaths were censored when modeling length of stay using Kaplan-Meier curves, and overall mortality was right censored at 10 years in all analyses to maintain samples of greater than 20 in each stratum. Subsequently, patient mortality analyses were expanded using multiple logistic (30-day mortality) and multiple proportional hazards regression (overall mortality) with backward selection to test whether the effect of ITA use differed or this effect depended on patient age, gender, BMI, STS-predicted 30-day mortality, or combinations of these (interactions). These models were initialized with all variables, as well as interactions with effects sequentially eliminated that were not statistically significant at the .05 level. Statistically significant interactions were interpreted on the basis of the simple effect hazard ratios (HRs), identifying significant simple effects as having $95 \%$ CIs that did not include 1.0. The proportionality assumption was checked by graphically comparing standardized score process functions for the observed to simulated paths. The observed path for the main effect of BMI was slightly out of range (low) near year 8 . No other observed paths had areas falling outside the simulations drawn from their null.

\section{RESULTS}

The study population consisted of 1141 patients (470 female/671 male). Group I (CABG-ITA) included 870 patients (339 female/531 male), and group II (CABG-SVG) included 271 patients (131 female/140 male).

\section{Demographics}

In group II (CABG-SVG), both male and female patients had a high incidence of preoperative heart failure $(P=.0483)$ (Table 1). The female cohort in group II (CABG-SVG) was older $(P=.0048)$, had a greater history of stroke $(P=.0596)$, and had higher STS scores $(P=.1)$. The female cohort in group I (CABG-ITA) had more patients with a left ventricular ejection fraction less than $30 \%(9.4 \%$ vs $3.8 \% ; P=.05)$. The male patients in group I had a higher STS score (0.7 vs $0.4 ; P=.06)$. Other demographic differences include higher BMI and greater incidence of dyslipidemia for patients receiving an ITA graft.

\section{Intraoperative Data}

Both men and women in group II (CABG-SVG) received fewer grafts $(2.5$ vs $3.2 ; P<.0001)$ and had shorter times (18-20 minutes) for the aortic crossclamp period and cardiopulmonary bypass $(P<.0001)$ compared with group I patients (CABG-ITA) (Table 2).

\section{Postoperative Outcome: Morbidity}

Male patients in group II male had longer lengths of stay than male patients in group I ( 9 vs 8 days; $P=.0071$ ), but there was no significant difference in the length of stay among female patients in group I versus group II $(P=.2292)$ (Tables 2 and 3$)$. Group II had a lower rate of postoperative complication in all patients $(P=.0499)$. Group II had a lower rate of pneumonia in all patients $(P=.0542)$. Male patients in group II had a lower rate of prolonged mechanical ventilation $(P=.0197)$.

\section{Survival}

The median follow-up was 5.8 years with an interquartile range of 2.8 to 9.0 years. The most common cause of hospital mortality or 30-day mortality was cardiac $40 \%$, followed by pulmonary complications, multiple organ failure, stroke, and renal failure. Table 3 reports postoperative morbidity, readmission, and 30-day mortality. Some $42 \%$ of patients were discharged to home, whereas $58 \%$ 
TABLE 1. Clinical characteristics of patients receiving a left internal thoracic artery as part of their bypass procedures compared with those not receiving an internal thoracic artery, stratified by gender

\begin{tabular}{|c|c|c|c|c|c|}
\hline & $\begin{array}{c}\text { ITA } \\
\text { Mean } / \%(95 \text { LCL, UCL })\end{array}$ & $\begin{array}{c}\text { No ITA } \\
\text { Mean/\% (95 LCL, UCL) }\end{array}$ & Interaction & Main effect of ITA & Effect of ITA by gender \\
\hline \multicolumn{6}{|l|}{ Age } \\
\hline Female & $82.5(82.2,82.7)$ & $83.2(82.7,83.7)$ & & & \\
\hline Male & $82.5(82.3,82.7)$ & $82.9(82.5,83.3)$ & $P=.2954$ & $P=.0018^{*}$ & \\
\hline \multicolumn{6}{|l|}{ BMI } \\
\hline Female & $26.3(25.8,26.8)$ & $25.7(24.9,26.6)$ & & & \\
\hline Male & $26.3(26.0,26.6)$ & $25.8(25.1,26.4)$ & $P=.8995$ & $P=.0668 \dagger$ & \\
\hline \multicolumn{6}{|l|}{ Hypertension } \\
\hline Female & $88.8(85.0,91.7)$ & $85.5(78.4,90.6)$ & & & \\
\hline Male & $84.0(80.6,86.9)$ & $81.4(74.1,87.0)$ & $P=.7666$ & $P=.2240$ & \\
\hline \multicolumn{6}{|l|}{ Dyslipidemia } \\
\hline Female & $61.7(56.4,66.7)$ & $60.3(51.7,68.3)$ & & & $P=.7882$ \\
\hline Male & $60.5(56.2,64.5)$ & $45.7(37.6,54.0)$ & $P=.0583 \dagger$ & & $P=.0019^{*}$ \\
\hline \multicolumn{6}{|l|}{ Diabetes } \\
\hline Female & $29.2(24.6,34.3)$ & $28.8(25.1,32.8)$ & & & \\
\hline Male & $28.8(25.1,32.8)$ & $23.6(17.3,31.3)$ & $P=.5571$ & $P=.2629$ & \\
\hline \multicolumn{6}{|l|}{ Smoking } \\
\hline \multicolumn{6}{|l|}{ Ever } \\
\hline Female & $22.7(18.6,27.5)$ & $22.1(15.8,30.1)$ & & & \\
\hline Male & $46.9(42.7,51.2)$ & $49.3(41.1,57.5)$ & $P=.6791$ & $P=.8406$ & \\
\hline \multicolumn{6}{|l|}{ Current } \\
\hline Female & $0.4(0.0,2.5)$ & $1.9(0.5,7.1)$ & & & \\
\hline Male & $3.4(2.0,5.6)$ & $1.7(0.4,6.7)$ & $P=.1051$ & $P=.4922$ & \\
\hline \multicolumn{6}{|l|}{$\mathrm{EF}$} \\
\hline \multicolumn{6}{|l|}{ Continuous } \\
\hline Female & $48.6(47.2,50.0)$ & $50.2(48.2,52.2)$ & & & \\
\hline Male & $48.2(47.2,49.3)$ & $47.9(45.9,49.8)$ & $P=.2468$ & $P=.4563$ & \\
\hline \multicolumn{6}{|l|}{$\mathrm{EF}<30$} \\
\hline Female & $9.4(6.8,13.1)$ & $3.8(1.6,8.9)$ & & & $P=.0501 \dagger$ \\
\hline Male & $9.4(7.2,12.2)$ & $10.7(6.6,17.0)$ & $P=.0571 \dagger$ & & $P=.6444$ \\
\hline \multicolumn{6}{|c|}{ Peripheral artery disease } \\
\hline Female & $20.7(16.7,25.3)$ & $23.7(17.2,31.7)$ & & & \\
\hline Male & $25.2(21.7,29.1)$ & $25.7(19.2,33.6)$ & $P=.6480$ & $P=.5417$ & \\
\hline \multicolumn{6}{|l|}{ CVA } \\
\hline Female & $7.4(5.0,10.7)$ & $13.0(8.2,19.9)$ & & & $P=.0596 \dagger$ \\
\hline Male & $9.4(7.2,12.2)$ & $7.1(3.9,12.8)$ & $P=.0586 \dagger$ & & $P=.4034$ \\
\hline \multicolumn{6}{|l|}{ Heart failure } \\
\hline Female & $31.6(26.8,36.7)$ & $37.4(29.5,46.0)$ & & & \\
\hline Male & $22.8(19.4,26.6)$ & $29.3(22.3,37.4)$ & $P=.7919$ & $P=.0483^{*}$ & \\
\hline \multicolumn{6}{|c|}{ STS 30-d risk of mortality } \\
\hline Female & $0.7(0.5,1.0)$ & $1.2(0.6,2.1)$ & & & $P=.1830$ \\
\hline Male & $0.7(0.6,0.9)$ & $0.4(0.3,0.7)$ & $P=.0273^{*}$ & & $P=.0631 \dagger$ \\
\hline
\end{tabular}

Female patients $\mathrm{n}=470$; male patients $\mathrm{n}=671$. Within-gender comparisons made for interactions with $P<.10$, otherwise main effect ITA inference applied to both genders. $B M I$, Body mass index; $C V A$, cerebrovascular accident; $E F$, ejection fraction; ITA, internal thoracic artery; LCL, lower confidence limit; STS, Society of Thoracic Surgeons; $U C L$, upper confidence limit. $* P<.05 . \dagger P<.10$.

went to extended care facilities, nursing homes, or rehabilitation facilities. Postoperatively, $80 \%$ of patients improved functional class. Long-term quality of life was not evaluated in this study. Figure 1 displays the long-term survival curves for both male and female patients distinguished by group and gender. Table 4 summarizes the final multiple logistic and multiple proportion hazards (Cox) regression models for 30-day and long-term survivals after backward selection.

The 30-day mortality (Tables 3 and 4) for the whole study population was $5.7 \%$. There was no statistically significant difference in 30-day mortality between groups: $4.3 \%$ in group I (CABG-ITA) and 7.0\% in group II (CABG-SVG) $(P=.1)$. The 30 -day mortality rate was $4.4 \%$ in group $\mathrm{I}$ 
TABLE 2. Operative parameters and length of stay of patients receiving left internal thoracic artery as part of their bypass procedure compared with those not receiving internal thoracic artery, stratified by gender

\begin{tabular}{|c|c|c|c|c|c|}
\hline & $\begin{array}{c}\text { ITA } \\
\text { Mean } / \%(95 \% \text { LCL, UCL })\end{array}$ & $\begin{aligned} & \text { No ITA } \\
\text { Mean } \% \% & (95 \% \text { LCL, UCL })\end{aligned}$ & Interaction & Main effect of ITA & Effect of ITA by gender \\
\hline \multicolumn{6}{|c|}{ Perfusion time } \\
\hline Female & $110.3(105.4,115.3)$ & $91.3(84.8,98.3)$ & & & \\
\hline Male & $112.3(107.5,117.4)$ & $91.2(84.2,98.8)$ & $P=.7567$ & $P<.0001 *$ & \\
\hline \multicolumn{6}{|c|}{ Crossclamp time } \\
\hline Female & $88.8(85.0,92.7)$ & $70.5(66.5,74.8)$ & & & \\
\hline Male & $92.2(89.1,95.4)$ & $72.5(67.5,77.8)$ & $P=.8497$ & $P<.0001 *$ & \\
\hline \multicolumn{6}{|c|}{ No. of grafts } \\
\hline Female & $3.1(3.0,3.2)$ & $2.5(2.4,2.7)$ & & & \\
\hline Male & $3.3(3.2,3.3)$ & $2.6(2.4,2.7)$ & $P=.5275$ & $P<.0001 *$ & \\
\hline \multicolumn{6}{|c|}{ LOS, d (75th percentile) } \\
\hline Female & $9.0(9.0,10.0)$ & $10.0(9.0,12.0)$ & & & $P=.2692$ \\
\hline Male & $8.0(8.0,9.0)$ & $9.0(9.0,11.0)$ & & & $P=.0071^{*}$ \\
\hline
\end{tabular}

Female patients $\mathrm{n}=470$; male patients $\mathrm{n}=671$. Within-gender comparisons made for interactions with $P<.10$, otherwise main effect ITA inference applied to both genders. Length of stay was compared using survival estimates, so no main effects or interactions were calculated. $I T A$, Internal thoracic artery; $L O S$, length of stay; $L C L$, lower confidence limit; $U C L$, upper confidence limit. $* P<.05$.

(CABG-ITA) female patients versus $8.4 \%$ in group II (CABG-SVG) $(P=.10)$. The 30-day mortality was $4.3 \%$ in group I (CABG-ITA) male patients versus $5.7 \%$ in group II (CABG-SVG) $(P=.5)$. Although the performance of an ITA-LAD graft was not associated with 30-day mortality, both patient age $(P=.0101)$ and STS-predicted 30-day mortality $(P=.0300)$ were significant (Table 4$)$. Because the STS prediction equation includes age, these predictors are nonindependent and their odds ratios are likely influenced to some degree by multicollinearity. BMI also interacted with gender $(P=.0157)$ such that higher BMI was associated with decreased risk of mortality ${ }^{10}$ in male patients (HR, 0.961 per unit; 95\% CI, 0.934-0.989) but not in female patients (HR, 1.008; 95\% CI, 0.983-1.035).

Figure 1 shows the Kaplan-Meier estimated survival functions for overall mortality for male (blue) and female (red) patients who received an ITA graft (solid) or an SVG (dash), along with the US Department of Health and Human Services Centers for Disease Control and Prevention life expectancy ${ }^{11}$ for male and female octogenarians. Overall, the long-term survival difference between male and female patients was not significantly different. The rate of decline paralleled that predicted by national statistics on a similar elderly population. As shown in Table 4 and by the Kaplan-Meier survival analysis (Figure 1), ITA interacted with gender $(P=.0101)$ reflecting a decreased risk of mortality associated with using an ITA in female patients (HR, 0.724; 95\% CI, 0.564-0.929). Female patients who received an ITA (solid red, 5 years: $70 \%, 10$ years: $35 \%$ ) had a long-term survival advantage over female patients who did not (dash red, 5 years: 63\%, 10 years: $21 \%$ ). In contrast, male patients (Figure 1) who received an ITA (solid blue, 5 years: $65 \%, 10$ years: $29 \%$ ) did not have a significant survival advantage $(P=.2385)$ over male patients who did not receive an ITA (dash blue, 5 years:
$69 \%$, 10 years: $31 \%$ ). Although not statistically significant, there was a survival tendency that favored survival (HR, $1.144 ; 95 \% \mathrm{CI}, 0.897-1.460$ ) for male patients in group II (CABG-SVG).

\section{Graft Patency}

Bypass graft patency could be assessed in only a minority of patients ( $\mathrm{N}=55$ or $4.8 \%$ ) who underwent cardiac catheterization for recurrent symptoms between 3 months and 10 years after surgery for recurrent symptoms. A total of 11 patients (CABG-ITA) had new clinically significant coronary stenoses in the distribution of the LAD, 8 of the 11 patients had developed lesions distal to the LAD-ITA graft anastomotic site, and 3 patients had ITA conduit stenosis while in another patients it was totally occluded.

In group II (CABG-SVG), all vein grafts to the LAD remained patent. A stenosis of another vein graft or a lesion distal to the graft developed in 18 patients. New lesions in native coronary arteries that had not received any bypass conduit in the initial surgery developed in 25 patients.

\section{DISCUSSION}

The ITA-LAD graft is the standard of care for all patients of any age with a high-grade stenosis of the LAD undergoing CABG. The present study demonstrates that the long-term survival benefits of the ITA-LAD bypass in the octogenarian population are gender specific and perhaps do not always favor the use of the ITA. Neither short nor long-term mortality outcomes for octogenarian male patients gave the appearance of being affected by the use of an ITA-LAD graft, which when considering the bias in clinical reasons for opting out of ITA use would suggest these clinical decisions mitigated at least some of the increased risk for poor outcomes in these patients. This further suggests that in the absence of a randomized clinical 
TABLE 3. Morbidity and mortality of patients receiving left internal thoracic artery as part of their bypass procedure compared with those not receiving internal thoracic artery, stratified by gender

\begin{tabular}{|c|c|c|c|c|c|}
\hline & $\begin{array}{c}\text { ITA } \\
\text { Mean } / \%(95 \text { LCL, UCL })\end{array}$ & $\begin{array}{c}\text { No ITA } \\
\text { Mean } / \%(95 \text { LCL, UCL })\end{array}$ & Interaction & $\begin{array}{l}\text { Main effect } \\
\text { of ITA }\end{array}$ & $\begin{array}{c}\text { Effect of ITA } \\
\text { by gender }\end{array}$ \\
\hline \multicolumn{6}{|c|}{ 30-d mortality } \\
\hline Female & $4.4(2.7,7.2)$ & $8.4(4.7,14.5)$ & & & \\
\hline Male & $4.3(2.9,6.4)$ & $5.7(2.9,11.0)$ & $P=.5056$ & $P=.0983 \dagger$ & \\
\hline \multicolumn{6}{|c|}{ 30-d readmission } \\
\hline Female & $11.7(8.7,15.7)$ & $7.5(3.9,13.8)$ & & & \\
\hline Male & $9.1(6.8,11.9)$ & $7.6(4.1,13.5)$ & $P=.5954$ & $P=.2577$ & \\
\hline \multicolumn{6}{|c|}{ Any complication } \\
\hline Female & $20.9(16.9,25.6)$ & $16.8(11.3,24.2)$ & & & \\
\hline Male & $18.5(15.4,22.0)$ & $12.1(7.7,18.7)$ & $P=.5705$ & $P=.0499^{*}$ & \\
\hline \multicolumn{6}{|c|}{ No. of complications } \\
\hline Female & $0.4(0.3,0.5)$ & $0.3(0.2,0.5)$ & & & \\
\hline Male & $0.4(0.3,0.4)$ & $0.2(0.1,0.4)$ & $P=.4222$ & $P=.0686 \dagger$ & \\
\hline \multicolumn{6}{|c|}{$\begin{array}{l}\text { Operation/reoperation } \\
\text { for bleeding }\end{array}$} \\
\hline Female & $3.2(1.8,5.8)$ & $3.8(1.6,8.9)$ & & & \\
\hline Male & $3.2(2.0,5.1)$ & $0.7(0.1,4.9)$ & $P=.1481$ & $P=.2465$ & \\
\hline \multicolumn{6}{|c|}{ Prolonged ventilation } \\
\hline Female & $15.6(12.1,19.9)$ & $14.5(9.4,21.6)$ & & & $P=.7604$ \\
\hline Male & $13.0(10.4,16.1)$ & $5.7(2.9,11.0)$ & $P=.0923 \dagger$ & & $P=.0197 *$ \\
\hline \multicolumn{6}{|l|}{ Pneumonia } \\
\hline Female & $5.0(3.1,7.9)$ & $0.8(0.1,5.2)$ & & & \\
\hline Male & $5.5(3.8,7.8)$ & $4.3(1.9,9.2)$ & $P=.1399$ & $P=.0542 \dagger$ & \\
\hline \multicolumn{6}{|c|}{ Pulmonary embolism } \\
\hline Female & $0.3(0.0,2.1)$ & $0.0(0.0,0.0)$ & & & \\
\hline Male & $0.2(0.0,1.3)$ & $0.7(0.1,4.9)$ & & & $P=.3452$ \\
\hline \multicolumn{6}{|c|}{ Renal failure } \\
\hline Female & $5.0(3.1,7.9)$ & $6.9(3.6,12.7)$ & & & \\
\hline Male & $5.8(4.1,8.2)$ & $4.3(1.9,9.2)$ & $P=.2906$ & $P=.9884$ & \\
\hline \multicolumn{6}{|l|}{ Dialysis } \\
\hline Female & $1.5(0.6,3.5)$ & $0.8(0.1,5.2)$ & & & \\
\hline Male & $1.5(0.8,3.0)$ & $1.4(0.4,5.5)$ & $P=.6525$ & $P=.5963$ & \\
\hline \multicolumn{6}{|c|}{ Infection/septicemia } \\
\hline Female & $3.0(1.6,5.4)$ & $3.1(1.2,7.9)$ & & & \\
\hline Male & $2.1(1.2,3.7)$ & $0.7(0.1,4.9)$ & $P=.3569$ & $P=.3884$ & \\
\hline \multicolumn{6}{|c|}{ Permanent stroke } \\
\hline Female & $1.8(0.8,3.9)$ & $0.0(0.0,0.0)$ & & & \\
\hline Male & $2.6(1.6,4.4)$ & $1.4(0.4,5.5)$ & & & $P=.4122$ \\
\hline \multicolumn{6}{|c|}{ Deep sternal wound infection } \\
\hline Female & $0.3(0.0,2.1)$ & $0.0(0.0,0.0)$ & & & \\
\hline Male & $0.9(0.4,2.2)$ & $0.7(0.1,4.9)$ & & & $P=.8000$ \\
\hline \multicolumn{6}{|l|}{ MI } \\
\hline Female & $2.1(1.0,4.4)$ & $0.9(0.1,6.1)$ & & & \\
\hline Male & $1.0(0.4,2.4)$ & $0.8(0.1,5.7)$ & $P=.6551$ & $P=.4898$ & \\
\hline
\end{tabular}

Female patients $\mathrm{n}=470$; male patients $\mathrm{n}=671$. Within-gender comparisons made for interactions with $P<.10$, otherwise main effect ITA inference applied to both genders. Comparisons not made when 1 or more groups had zero events. ITA, Internal thoracic artery; $L C L$, lower confidence level; $M I$, myocardial infarction; $U C L$, upper confidence limit. $* P<.05 . \dagger P<.10$.

trial, male octogenarians undergoing CABG without an ITA might do even better.

In contrast, long-term survival was significantly improved for octogenarian female patients receiving an ITA-LAD conduit. However, when considered in the context of the bias by the clinical decisions leading to
ITA use, this conclusion has to be questioned because nonuse of the ITA would be expected only in frail patients, and on the same note, poorer outcomes would be anticipated in frail patients. Therefore, the bias represents a consistent, alternative explanation for the superiority of ITA use in our female octogenarians. In addition, given 
TABLE 4. Thirty-day and overall mortality: Backward selection multiple predictor models

\begin{tabular}{|c|c|c|c|}
\hline & OR & $95 \% \mathrm{CI}$ & $P$ value \\
\hline \multicolumn{4}{|l|}{ 30-d mortality: Final model } \\
\hline Patient age (per y) & 1.131 & $1.030-1.242$ & .0101 \\
\hline \multirow[t]{2}{*}{$\begin{array}{l}\text { STS } 30-d \text { predicted mortality } \\
\text { (per percent) }\end{array}$} & 1.084 & $1.008-1.666$ & .0300 \\
\hline & HR & $95 \% \mathrm{CI}$ & $P$ value \\
\hline \multicolumn{4}{|l|}{ Overall mortality: Final model } \\
\hline Patient age (per y) & 1.088 & $1.057-1.119$ & $<.000$ \\
\hline BMI (per unit) & & & .0073 \\
\hline Gender (female vs male) & & & .0595 \\
\hline BMI gender & & & .0157 \\
\hline BMI (per unit) in women & 1.008 & $0.983-1.035$ & \\
\hline BMI (per unit) in men & 0.961 & $0.934-0.989^{*}$ & \\
\hline Any ITA used & & & .2783 \\
\hline Gender $\times$ any ITA used & & & .010 \\
\hline Any ITA in women & 0.724 & $0.564-0.929 *$ & \\
\hline Any ITA in men & 1.144 & $0.897-1.460$ & \\
\hline
\end{tabular}

All models started with patient age, BMI, gender, any ITA, STS-predicted mortality, and all possible interactions. Backward selection was used to iteratively remove the weakest nonsignificant predictors (alpha $=0.05$ ). BMI, Body mass index; $C I$, confidence interval; $H R$, hazard ratio; ITA, internal thoracic artery; $O R$, odds ratio; STS, Society of Thoracic Surgeons. $* P<.05$.

the 30-day mortality rate of $8.4 \%$ in patients who were revascularized without an ITA graft, some of these early deaths may contribute significantly to the late mortality difference observed. This survival advantage likely can be due to an increased rate of postoperative complications, including pneumonia and prolonged mechanical ventilation.

In their seminal article, Loop and colleagues ${ }^{5}$ established the superiority of the ITA over an SVG as the preferred conduit to a diseased LAD by demonstrating significantly greater 10-year survival in the ITA-LAD group in patients undergoing surgical revascularization. Additional outcome benefits include reductions in hospital readmissions, late myocardial infarctions, and cardiac reoperations. Other data $^{7,12}$ have confirmed the long-term benefits in both survival and freedom from late cardiac events of the ITA-LAD grafts, some extending into the second decade. These studies ${ }^{6,7}$ describe patients undergoing CABG surgery, in the 1970s and 1980s, with a mean age less than 60 years. By using a subset of the STS National Cardiac Database from 1996 to 1999, Ferguson and colleagues $^{13}$ reported a reduced 30-day perioperative mortality rate associated with performance of an arterial graft ITA versus all vein grafts in approximately 100,000 patients who were aged 75 years or more who underwent primary elective CABG. This finding, which remained significant when risk adjusted for patient characteristics, led to the recommendations that ITA grafts be performed in the elderly and should be used as a quality indicator in patients of all ages undergoing CABG. It is disappointing that long-term survival was not investigated in that study. When analyzed further, the acute survival benefits of an ITA graft diminished with advanced age ( $>85$ years) and decreasing ejection fraction.

Several studies ${ }^{6,7,12-16}$ have demonstrated higher graft patency rates with ITA-LAD grafts compared with SVG-LAD grafts. Thus, use of an ITA-LAD graft in elderly patients has increased over the past 10 to 15 years and has been associated with improved outcomes. ${ }^{14-17}$ As demonstrated in the present study, it is not known whether its survival benefits apply equally to all elderly patients (Figure 1).

The elderly cardiac surgical patient is at increased risk for perioperative mortality and morbidity and requires increased resources in the operative period. ${ }^{15,17-19}$ The slower adoption of the ITA-LAD graft in the higher-risk elderly patient population reflects concerns over increasing morbidity due to sternal wound breakdown or infection, pulmonary dysfunction, phrenic nerve injury, or excessive postoperative bleeding. In the present study, performance of an ITA-LAD bypass graft was associated with increased postoperative complications, including pneumonia $(P=.05)$ and prolonged mechanical ventilation.

In the present study, 30-day mortality ranged from $4.3 \%$ to $8.4 \%$. Lower rates of operative mortality were reported in men from both groups and in women receiving an ITA-LAD graft. Group II (CABG-SVG) men had a 30-day mortality of $5.7 \%$, which was not statistically significantly different from group I (ITA-LAD) men at $4.3 \%$. There were no demographic differences between the 2 subgroups of male patients. The highest 30-day mortality $(8.4 \%)$ occurred in group II octogenarian female patients (CABG-SVG). It is notable that the group I octogenarian female patients (ITA-LAD) were significantly younger and had less vascular disease, both variables known to be associated with a better perioperative outcome. Regardless, the benefit of the ITA-LAD graft was clearly demonstrated in the octogenarian female patient (Figure 1).

Octogenarian female patients who received an ITA-LAD graft had a 5-year and 10-year survival advantage over those who did not ( $70 \%$ vs $63 \%$ and $35 \%$ vs $21 \%$, respectively), whereas no outcome advantage was demonstrated among the men at each milestone. A review of the literature yields similar 5-year survival ranging from $45 \%$ to $74.5 \% .{ }^{17-21} \mathrm{~A}$ retrospective observational analysis of approximately 1062 octogenarians by Kurlansky and colleagues ${ }^{15,16}$ reported an operative mortality advantage in patients receiving an arterial graft (almost always to the LAD). However, there was no long-term advantage for cardiac morbidity (nonfatal myocardial infarction, percutaneous coronary intervention, reoperation rates, or mortality) in those who received an arterial graft versus those who did not. Review of the preoperative patient characteristics in their studies 
indicated that the vein graft only group was at higher risk for perioperative mortality and morbidity, and that other variables may have contributed to their higher 30-day mortality rate. An ITA was used in only $41.5 \%$ of patients in their studies.

Also, comparison of survival by gender demonstrated survival by male patients to be $52.4 \% \pm 2 \%$ at 5 years and $21.6 \% \pm 1.8 \%$ at 10 years, whereas survival for female patients was $62.2 \% \pm 2.4 \%$ at 5 years and $27.7 \% \pm 2.4 \%$ at 10 years. The comparison also revealed a significant difference $(P=.004)$ demonstrating that women in this study had enhanced survival relative to men. They did not look into the choice of conduit on the long-term survival benefit.

Aziz and colleagues ${ }^{20}$ and others ${ }^{21-23}$ evaluated preoperative and intraoperative factors associated with long-term survival in octogenarian patients undergoing isolated CABG. Of all the intraoperative variables studied, only time spent on cardiopulmonary bypass was associated with long-term survival. Other patient-specific risk factors, such as age, preoperative renal dysfunction on dialysis, diabetes, surgical selection bias, and severe left ventricular dysfunction, seemed to influence long-term survival, but the performance of the ITA-LAD graft did not. Of note, their study population of octogenarians was predominantly male $(61.7 \%)$.

Group II (CABG-SVG) octogenarian female patients had a greater operative and long-term mortality than any of the other groups. Consistent with other investigations, ${ }^{16-20,22}$ demographic data may have contributed toward this outcome. Of note, the female patient cohort in group II was older and had higher preoperative STS score, both of which are associated with greater operative mortality. Another possible explanation involves vascular conduit mismatch between the bypass conduits and the distal arterial vessel. If it is assumed that the coronary arterial vessels of female patients are smaller than those of men, then it is possible that anatomic mismatch may be more significant in the female patient when relatively larger diameter SVGs are used instead of the smaller diameter ITA. In addition, this group was higher risk, which also might have added to the higher 30-day mortality in group II female patients than in the other 3 groups.

The gender-related benefit of ITA-LAD on long-term mortality reported in this study might be explained by understanding natural life expectancies. In the general population, a person aged more than 90 years has an average life expectancy of 3 years. ${ }^{11}$ At 80 years of age, the life expectancy is 9 years for women and 5 years for men. ${ }^{11}$ Kurlansky and colleagues ${ }^{16}$ reported a mean survival of 5.9 years in more than 1000 octogenarians undergoing isolated CABG surgery. When separated by gender, the mean survival in female patients was significantly greater (6.7 years) than in their male counterparts (5.2 years).
Outcomes for the elderly cardiac surgical patient may be unaffected by the selection of the bypass conduit if life expectancy is only 5 years, as is the case with octogenarian men. ${ }^{11}$ By contrast, the type of vascular conduit (ITA) may have a greater impact on patients with a longer life expectancy, as would be the case for octogenarian female patients. Octogenarian female patients are more likely to live long enough to experience the benefits of having or complications of not having an ITA to LAD graft. If analysis of a study population does not distinguish between genders, the general outcome result may reflect which gender is more dominant.

The present study does not refute the benefits of performing an ITA-LAD graft in most cardiac surgical patients, but does offer an explanation as to why some octogenarian patients may not benefit. Given the concerns of adverse consequences, use of the ITA should be considered individually, especially for patients of an advanced age. For patients with an expected shortened life expectancy or at greater risk for pulmonary dysfunction, using an ITA-LAD graft may have less benefit. Data and results generated from younger patient populations are not easily extrapolated to the very elderly patient population, and gender may make differences in outcomes. ${ }^{24}$ Although the present study's results appear to conflict with the literature, they actually support the use of ITA conduit and further identify which patient subgroups might benefit more.

To the best of our knowledge, the gender-specific survival benefit of the ITA-LAD graft in the octogenarian has not been reported. The present study should prompt researchers to reassess general population data to see whether there are subsets of groups who do or do not benefit from specific surgical procedures instead of generalizing applicability of results to all populations undergoing similar procedures.

\section{Study Limitations}

Retrospective studies have inherent limitations, particularly with regard to sampling bias. In this case, the sampling bias serves to underscore our findings that male patients in whom an intraoperative decision not to use ITA was made because of anticipated greater risk and poorer health did not ultimately have poorer outcomes than those who the surgeon decided were stable/healthy enough to undergo the procedures involved in using ITA. This sampling bias leaves open the question of interpretation in female patients, in whom there was a similar sampling bias, but for whom there are also theoretic reasons to expect superior benefits of ITA relative to male patients.

Also, the decision not to use the ITA was not randomly assigned, but instead determined on the basis of the decision of an experienced surgeon, the urgency of the operation, the frailty of the patient, and the patient's condition. There was 
no objective evaluation of frailty ${ }^{6}$ or documentation of quality of distal vessel.

Comparing the present study with that reported in the literature is challenging because of differences in the populations. The present study included patients undergoing elective isolated CABG with a BMI less than $50 \mathrm{~kg} / \mathrm{m}^{2}$. As described earlier, exclusion of emergency cases or patients with obesity or renal failure may have altered the results of the present study. ${ }^{16}$ Given that these variables contribute toward adverse outcomes, it is possible that any beneficial impact of the ITA-LAD may have been reduced or eliminated. ${ }^{16,21-23}$

Although there was no difference in mortality and morbidity at the 2 institutions in this study, we understand the limitations despite the fact that our surgeons continued the same protocols and algorithms for the care of the cardiac surgical patient during the perioperative period. Causes of long-term mortality were not researched. Because this group represents octogenarians aged more than 80 years, it is possible that causes of long-term mortality were less related to cardiac dysfunctions. Nevertheless, the results demonstrate an association between performance of the ITA-LAD graft and outcome for octogenarian female patients.

\section{CONCLUSIONS}

This study shows that the benefits of the ITA in the octogenarian patient population undergoing CABG may be gender related. For the octogenarian female patient, use of the ITA as a bypass conduit was associated with superior long-term survival compared with those for whom the ITA was not used. To make decisions on the basis of findings taken from nonspecific or younger population databases may not be in the best interest of smaller, specific groups such as the octogenarian population. Future studies that include this information would be better able to stratify randomization in a randomized clinical trial or conduct a matched sampling of patients on these measures, in which case the test of ITA versus SVG would more closely approximate the effects of randomization.

\section{Conflict of Interest Statement}

Authors have nothing to disclose with regard to commercial support.

\section{References}

1. Centers for Disease Control and Prevention. National Vital Statistics Reports. Vol. 60, No. 6, June 2012. Available at: http://www.cdc.gov/nchs/nvsr. Accessed January 2014.

2. Epstein AJ, Polsky D, Yang F, Yang L, Groeneveld PW. Coronary revascularization trends in the United States, 2001-2008. JAMA. 2011;305: 1769-76.

3. Dacey LJ, Likosky DS, Ryan TJ Jr, Robb JF, Quinn RD, DeVries JT, et al. Long-term survival after surgery versus percutaneous intervention in octogenarians with multivessel coronary disease. Ann Thorac Surg. 2007;84:1904-11.
4. Saxena A, Dinh DT, Yap CH, Reid CM, Billah B, Smith JA, et al. Critical analysis of early and late outcomes after isolated coronary artery bypass surgery in elderly patients. Ann Thorac Surg. 2011;92:1702-11.

5. Loop FD, Lytle BW, Cosgrove DM, Stewart RW, Goormastic M, Williams GW, et al. Influence of the internal-mammary-artery graft on 10-year survival and other cardiac events. N Engl J Med. 1986;314:1-6.

6. Sündermann SH, Dademasch A, Seifert B, Rodriguez Cetina Biefer H, Emmert MY, Walther T, et al. Frailty is a predictor of short- and mid-term mortality after elective cardiac surgery independently of age. Interact Cardiovasc Thorac Surg. 2014;18:580-5.

7. Mediratta N, Chalmers J, Pullan M, McShane J, Shaw M, Poullis M. In-hospital mortality and long-term survival after coronary artery bypass surgery in young patients. Eur J Cardiothorac Surg. 2013;43:1014-21.

8. STS. Adult Cardiac Surgery Database Data Specifications. Version 2.81, July 2014. Accessed August 2014.

9. Singh AK, Feng WC, Bert AA, Rotenberg FA. Warm body, cold heart: myocardial revascularization in 2383 consecutive patients. J Cardiovasc Surg. 1993;34:415-21

10. Stamou SC, Nussbaum M, Stiegel RM, Reames MK, Skipper ER, Robicsek F, et al. Effect of body mass index on outcomes after cardiac surgery: is there an obesity paradox? Ann Thorac Surg. 2011;91:42-7.

11. United States Department of Human Services. Life Tables, 2009. National Vital Statistics Report Volume 62, Number 07. 63 pp. Available at: http://www.cdc. gov/nchs/data/nvsr/nvsr62/nvsr62_07.pdf. Accessed January 2014.

12. Sabik JF III, Lytle BW, Blackstone EH, Houghtaling PL, Cosgrove DM Comparison of saphenous vein and internal thoracic artery graft patency by coronary system. Ann Thorac Surg. 2005;79:544-51.

13. Ferguson TB, Coombs LP, Peterson ED. Internal thoracic artery grafting in the elderly patient undergoing coronary artery bypass grafting: room for process improvement? J Thorac Cardiovasc Surg. 2002;123:869-80.

14. Gardner TJ, Greene PS, Rykiel MF, Baumgartner WA, Cameron DE, Casale AS, et al. Routine use of the left internal mammary artery graft in the elderly. Ann Thorac Surg. 1990;49:88-194.

15. Kurlansky PA, Williams DB, Traad EA, Carrillo RG, Schor JS, Zucker M, et al. Arterial grafting results in reduced operative mortality and enhanced long-term quality of life in octogenarians. Ann Thorac Surg. 2003;76:418-27.

16. Kurlansky PA, Williams DB, Traad EA, Zucker M, Ebra G. Eighteen-year follow-up demonstrates prolonged survival and enhanced quality of life for octogenarians after coronary artery bypass grafting. J Thorac Cardiovasc Surg. 2011;141:394-9.

17. Hirose H, Amano A, Takahashi A. Coronary artery bypass grafting for octogenarians: experience in a private hospital and review of the literature. Ann Thorac Cardiovasc Surg. 2001;7:282-91.

18. Scott BH, Seifert FC, Grimson R, Glass PS. Octogenarians undergoing coronary artery bypass graft surgery: resource utilization, postoperative mortality, and morbidity. J Cardiothorac Vasc Anesth. 2005;19:583-8.

19. Alexander KP, Anstrom KJ, Muhlbaier LH, Grosswald RD, Smith PK, Jones RH, et al. Outcomes of cardiac surgery in patients $\geq 80$ years: results from the National Cardiovascular Network. J Am Coll Cardiol. 2000;35:731-8.

20. Aziz A, Lee AM, Pasque MK, Lawton JS, Moazami N, Damiano RJ, et al. Evaluation of revascularization subtypes in octogenarians undergoing coronary artery bypass grafting. Circulation. 2009;120:S65-9.

21. Mohammadi S, Kalavrouziotis D, Dagenais F, Voisine P, Charbonneau E Completeness of revascularization and survival among octogenarians with triple-vessel disease. Ann Thorac Surg. 2012;93:1432-8.

22. Rohde SL, Baker RA, Tully PJ, Graham S, Cullen H, Knight JL. Preoperative and intraoperative factors associated with long-term survival in octogenarians cardiac surgery patients. Ann Thorac Surg. 2010;89:105-11.

23. Kim KB, Hwang HY, Hahn S, Kim JS, Oh SJ. A randomized comparison of the Saphenous Vein Versus Right Internal Thoracic Artery as a Y-Composite Graft (SAVE RITA) trial: one-year angiographic results and mid-term clinical outcomes. J Thorac Cardiovasc Surg. 2014;148:901-7.

24. Pullan M, Kirmani BH, Conley T, Oo A, Shaw M, McShane J, et al. The effect of patient sex on survival in patients undergoing isolated coronary artery bypass surgery receiving a radial artery. Eur J Cardiothorac Surg. 2015;47: 324-30.

Key Words: coronary artery bypass grafting, elderly, internal thoracic artery, saphenous vein 